\title{
An unexpected liver lesion?
}

T. De Somer' ${ }^{1}$, M. D’Hondt ${ }^{2}$, K. Carels ${ }^{3}$, E. Monsaert ${ }^{1}$, V. Bouderez ${ }^{1}$, E. Vanderstraeten ${ }^{1}$, H. Alaerts ${ }^{4}$, C. Van Steenkiste ${ }^{1,5}$

(1) Department of Gastroenterology and Hepatology, Maria Middelares Hospital, Buitenring Sint-Denijs 30, 9000 Gent, Belgium ; (2) Department of Abdominal Surgery, AZ Groeninge Hospital, President Kennedylaan 4, 8500 Kortrijk, Belgium ; (3) Department of Radiology, Maria Middelares Hospital, Buitenring Sint-Denijs 30, 9000 Gent, Belgium ; (4) Department of Histopathology, AZ Groeninge Hospital, President Kennedylaan 4, 8500 Kortrijk, Belgium ; (5) University Hospital Antwerp, Wilrijkstraat 10, 2650 Edegem, Belgium.

\section{Case}

A 50-year-old woman presented with pain in her right upper abdomen. In her medical history we note a Caesarean section and a laparotomy with bilateral ovariectomy because of benign cysts. The liver enzymes were mildly elevated: aspartate transaminase $40 \mathrm{U} / 1$ (reference $<32 \mathrm{U} / \mathrm{l}$ ), alanine transaminase $53 \mathrm{U} / 1$ (reference $<31 \mathrm{U} / 1$ ), gamma-glutamyl transferase $97 \mathrm{U} / 1$ (reference $5-36$ ). Computed tomography (CT) revealed a large lesion in the right liver lobe with a cyst within cyst appearance and with important compression of the surrounding tissue (figure 1, panel A). The total diameter measured $29 \mathrm{~cm}$ by $17 \mathrm{~cm}$ by $22 \mathrm{~cm}$. A perioperative image is shown in figure 1 panel $\mathrm{B}$.

\section{What is your diagnosis?}

1. Hemorrhagic biliary cyst

2. Mucinous cystadenoma

3. Endometrial cyst

4. Echinococcal cyst

\section{Discussion}

A small, contrast enhancing proliferation was seen anteromedially in the peripheral cyst (figure 1, panel A). Magnetic resonance imaging (MRI) showed a watery content in the internal cyst (high signal on T2 and low on T1) and a hyperintense T1 signal in the peripheral cyst, suggestive for hemorrhagic content.

During laparoscopic exploration both cysts were incised with evacuation of 3 liters of serosanguineous and 3 liters of serous fluid. Subsequently, the whole cystic lesion was resected (figure 2, panel A). Histopathological examination revealed the diagnosis of an endometrial cyst (figure 2, panel B).

Endometriosis is defined as the presence of endometrial tissue outside the uterus $(1,2)$. Hepatic endometrial cysts appear to be rare with only case reports available in the literature. Preoperative diagnosis is challenging, since no clinical or radiological findings are characteristic $(2,3)$. As a consequence, surgery is the next step for both diagnostic confirmation and treatment $(1,3)$. Since perioperative frozen sections can confirm the diagnosis,
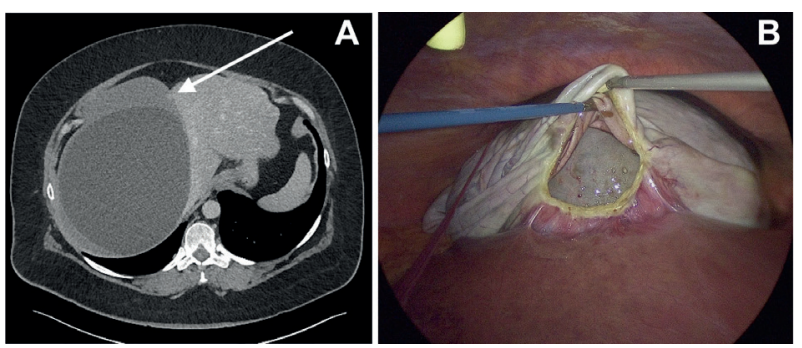

Figure 1. - panel A: contrast enhanced axial computed tomography image: spontaneous isodense aspect of the peripheral cyst and hypodense aspect of the internal cyst, arrow: small contrast enhancing proliferation; panel B: perioperative image after incision of the peripheral cyst.
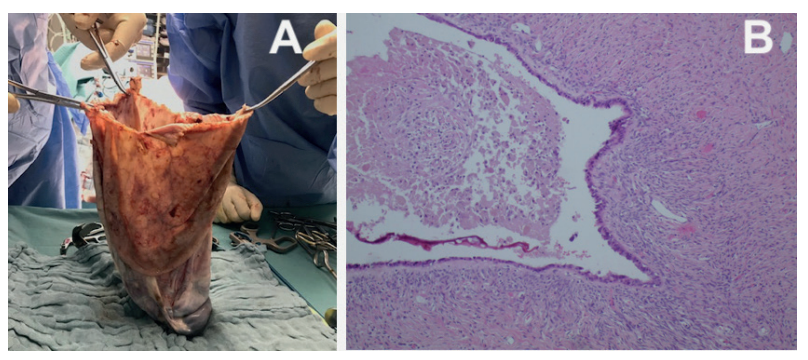

Figure 2. - panel A: image of the resected lesion; panel B: histopathological image (magnification $\mathrm{x} 100$ ) with intraluminal blood and macrophages, endometrial type epithelium and endometrial stroma in the wall of the cyst.

radical hepatectomy sometimes can be avoided and pericystectomy can be performed (2,3). Unlike the other possible diagnoses this endometrial cyst was not actually a liver lesion, but a lesion against the liver.

\section{Conflicts of interest}

None declared.

Keywords : Abdominal pain, endometrial cyst, hepatic endometriosis.

Correspondence to : Thomas De Somer, Buitenring Sint-Denijs 30, 9000 Gent, Belgium. Fax : 09/246.71.09.

Email : thomasdesomer@gmail.com

Submission date : 04/05/2020

Acceptance date : 30/06/2020 


\section{References}

1. ZONDERVAN K.T., BECKER C.M., MISSMER S.A. Endometriosis. N. Engl. J. Med., 2020, 382(13) : 1244-56.

2. PRODROMIDOU A., MACHAIRAS N., PASPALA A., HASEMAKI N., SOTIROPOULOS G.C. Diagnosis, surgical treatment and postoperative outcomes of hepatic endometriosis: A systematic review. Ann. Hepatol., 2020, 19(1) : 17-23.

3. ANDRES M.P., ARCOVERDE F.V.L., SOUZA C.C.C., FERNANDES L.F.C., ABRAO M.S., KHO R.M. Extrapelvic endometriosis: A systematic review. J. Minim. Invasive Gynecol., 2020, 27(2) : 373-89. 